\title{
Tracing the associations between sex, the atypical and the combined atypical- melancholic depression subtypes: a path analysis
}

\author{
Stephanie Rodgers ${ }^{1 *}$, Caroline L. Vandeleur ${ }^{2}$, Vladeta Ajdacic-Gross ${ }^{1}$, Aleksandra A. \\ Aleksandrowicz, Marie-Pierre F. Strippoli ${ }^{2}$, Enrique Castelao ${ }^{2}$, Jennifer Glaus $^{2,3}$, Aurélie M. \\ Lasserre $^{2}$, Mario Müller ${ }^{1}$, Wulf Rössler ${ }^{1,2,3,4,5}$, Jules Angst ${ }^{1}$, Martin Preisig ${ }^{2}$ \\ ${ }^{1}$ Department of Psychiatry, Psychotherapy and Psychosomatics, Psychiatric Hospital, University of \\ Zurich, Switzerland \\ ${ }_{2}^{2}$ Psychiatric Epidemiology and Psychopathology Research Center, Department of Psychiatry, \\ Lausanne University Hospital, Lausanne, Switzerland \\ ${ }^{3}$ Genetic Epidemiology Research Branch, Intramural Research Program, National Institute of Mental \\ Health, Bethesda, MD, USA \\ ${ }^{4}$ Collegium Helveticum, University of Zurich and Swiss Federal Institute of Technology, Zurich, \\ Switzerland \\ ${ }^{5}$ Institute of Psychiatry, Laboratory of Neuroscience (LIM 27), University of Sao Paulo, Brazil
}

Revised manuscript submitted to:

Journal of Affective Disorders

(Original paper)

*Corresponding author:

Stephanie Rodgers

Department of Psychiatry, Psychotherapy and Psychosomatics

Psychiatric Hospital, University of Zurich

PO Box 1930 
CH-8021 Zurich

Switzerland

Tel: 0041-44-296 7422

Fax: 0041-44-296 7309

E-mail: stephanie.rodgers@dgsp.uzh.ch 


\section{Abstract}

\section{Background:}

Numerous studies have examined determinants leading to preponderance of women in major depressive disorder (MDD), which is particularly accentuated for the atypical depression subtype. It is thus of interest to explore the specific indirect effects influencing the association between sex and established depression subtypes.

\section{Methods:}

The data of 1624 subjects with a lifetime diagnosis of MDD derived from the population-based PsyCoLaus data were used. An atypical $(n=256)$, a melancholic $(n=422)$, a combined atypical and melancholic features subtype ( $n=198)$, and an unspecified MDD group $(n=748)$ were constructed according to the DSM-IV specifiers. Path models with direct and indirect effects were applied to the data.

\section{Results:}

Partial mediation of the female-related atypical and combined atypical-melancholic depression subtypes was found. Early anxiety disorders and high emotion-orientated coping acted as mediating variables between sex and the atypical depression subtype. In contrast, high Body Mass Index (BMI) served as a suppression variable, also concerning the association between sex and the combined atypical-melancholic subtype. The latter association was additionally mediated by an early age of MDD onset and early/late anxiety disorders.

\section{Limitations:}

The use of cross-sectional data does not allow causal conclusions.

\section{Conclusions:}


This is the first study that provides evidence for a differentiation of the general mechanisms explaining sex differences of overall MDD by depression subtypes. Determinants affecting the pathways begin early in life. Since some of them are primarily of behavioral nature, the present findings could be a valuable target in mental health care.

Keywords: Depression, atypical and melancholic subtypes, sex, epidemiology. 


\section{Introduction}

The impetus to differentiate the psychopathological phenotype of Major Depressive Disorder (MDD) is provided by accumulating empirical evidence demonstrating that this disorder subsumes different symptom clusters/subtypes. Separate lines of studies applying data-driven methodological techniques, such as latent class analysis (Alexandrino-Silva et al., 2013; Kendler et al., 1996; Lamers et al., 2012a; Lamers et al., 2010; Rodgers et al., 2014a; Rodgers et al., 2014b; Sullivan et al., 1998; Sullivan et al., 2002), factor analysis (Li et al., 2014; Serretti et al., 1998), principal components analysis (Basoglu, 1984; Haslam and Beck, 1993) and cluster analysis (Andreasen and Grove, 1982; Fountoulakis et al., 1999; Maes et al., 1990; Schotte et al., 1997) have confirmed the existence of atypical and/or melancholic (also referred to as typical or endogenous) symptom subtypes. Both depression symptom subtypes are included in the current version of the Diagnostic and Statistical Manual of Mental Disorders (DSM-5; APA, 2013) as MDD specifiers 'with atypical features' and 'with melancholic features', respectively. The atypical depression subtype was particularly characterized by the presence of either reverse vegetative symptoms of hypersomnia or hyperphagia in a nationally representative sample (Blanco et al., 2012). Beyond their delimitable symptom profiles, and certain psychosocial characteristics, recent studies strongly supported the differentiation of atypical and melancholic depression subtypes with respect to their pathophysiological markers and mechanisms, e.g., obesity (Antonijevic, 2006; Baumeister and Parker, 2012; Gold and Chrousos, 2002; Lamers et al., 2013; Lasserre et al., 2014). Although a consistent body of literature has documented the differentiation of atypical and melancholic depression, the exact etiologic mechanisms of these subtypes are far from being understood. From a longitudinal perspective, the atypical and melancholic/typical subtypes have been shown to be stable, particularly with regard to the atypical group (Lamers et al., 2012b; Rodgers et al., 2014a). However, these two subtypes exhibit a considerable overlap in nearly half of all cases (Angst et al., 2007), and moreover, include a group of subjects fluctuating between atypical and melancholic/typical episodes (Levitan et al., 1997; Rodgers et al., 2014a). The fluctuating group was shown to suffer from affective dysregulation, impulsivity and severe psychopathology (Levitan et al., 1997) and the changing profiles of melancholic and atypical depression profiles were hypothesized to result from a "hypothalamic switch" in the regulation of the hypothalamic-pituitary-adrenal (HPA) 
system (O'Keane et al., 2012). However, this hypothesis still needs further validation. In any case, Angst and colleagues (2007) suggested that future research should also consider a combined subgroup comprised of subjects with both atypical and melancholic features.

A particularly interesting feature of these depression subtypes is the marked preponderance of women in atypical depression (Angst et al., 2002; Benazzi, 1999; Halbreich and Kahn, 2007; Moskvina et al., 2008; Posternak and Zimmerman, 2001). So far, few studies have investigated specific mechanisms in relation to the female-related atypical depression subtype. On the other hand, a considerable number of studies have focused on the general mechanisms explaining sex differences of overall MDD (Kuehner, 2003; Piccinelli and Wilkinson, 2000), as illustrated in the following section.

The association between sex and early age of onset of MDD has been reported for women (Kornstein et al., 2000; Marcus et al., 2005; Moskvina et al., 2008; Schuch et al., 2014). Accounting for comorbid conditions, Breslau et al. $(1998 ; 1995)$ attributed a considerable portion of the sex differences in MDD to prior anxiety disorders, which are more common in women. In cases where men had been previously affected by anxiety disorders, they were however as vulnerable as women to become depressed. In terms of personality factors, neuroticism was broadly replicated as a robust risk factor for MDD (Boyce et al., 1991; Hirschfeld et al., 1989; Kendler et al., 1993; Sjoholm et al., 2009), particularly among women (Kendler and Gardner, 2014). Moreover, the latter study distinguished low parental warmth, divorce, low social support, and low marital satisfaction as female-related risk factors in the etiologic pathway to MDD, whereas variables such as childhood sexual abuse, prior history of MDD, certain stressful life events (related to financial, work and legal problems) and drug abuse were determined to be male-related risk factors (Kendler and Gardner, 2014). Further evidence with regard to female-associated risk factors for overall MDD stem from studies focusing on coping styles. Emotion-oriented and ruminative coping style were more frequently reported by depressed women than men (Hildebrandt et al., 2003; Nolen-Hoeksema, 2012), and emotion-oriented coping was associated with high depression scores in both sexes (Endler and Parker, 1990; Ravindran et al., 1995). From the large number of proposed coping styles, Parker and Endler (1992) emphasized that many of 
them could be clustered around the basic dimensions of problem-orientated coping, emotionorientated coping and avoidance strategy. While the problem-orientated coping style is directed at reducing or removing a stressor and tends to be used in subjectively controllable situations, emotionorientated coping is aimed at reducing and managing the emotional distress and tends to be used in uncontrollable appraised situations (Carver et al., 1989; Dunn and Conley, 2015; Folkman and Lazarus, 1980, 1988). A recently published review even found evidence for a genetic variation explaining coping phenotypes, however, these findings are based on sparse data and replication is required (Dunn and Conley, 2015).

With regard to specific mechanisms between sex and atypical depression, Angst et al. (2002) emphasized that the consistently found reports of an earlier age of onset may be an indicator of severity, and that women may have an earlier age at onset of atypical depression. Halbreich and Kahn (2007) revealed the high prevalence of atypical depression during the perimenopause period, suggesting involvement of hormone instability in its pathobiology. Apart from these findings, there is not much knowledge about the reasons for the preponderance of women in atypical depression.

In summary, the perspectives of the risk factors considered can be distinguished as follows: general risk factors focusing on sex-differences of overall MDD (partly also applying to depressed men) on the one hand, versus specific risk factors focusing on sex-differences related to depressive subtypes and sex-specificity, respectively, on the other. Taking into account the explanation of the femalerelated risk for MDD resulting from the phenotype of atypical depression, we are actually faced with nested risk factors. Based on the growing consensus that atypical depression and melancholic depression are well distinguishable, particularly with regard to weight-/appetite associated features (Benazzi, 2002), there is a need to better understand the links between sex, general and specific risk factors and these MDD subtypes.

In the present study we examined the pathways between sex and the MDD subgroups atypical depression, melancholic depression, a combined subgroup (including subjects with both melancholic 
and atypical features) and an unspecified MDD group by applying path analysis to a community sample of Swiss adults. We aimed to clarify the potential mediating or suppressing effects of general and sex-related risk factors, based on the literature (such as age of onset of MDD, comorbid anxiety disorders, substance use, obesity, personality traits, coping styles, childhood adversities, and parental bonding) as regards their influence on the relation between sex and these depression subtypes.

\section{Material and methods}

\subsection{Sample}

The data of the current paper stem from the baseline data of the PsyCoLaus study (Preisig et al., 2009), which is the psychiatric branch of the CoLaus study (Firmann et al., 2008). Both PsyCoLaus and CoLaus are prospectively designed cohort studies. A major goal of PsyCoLaus was that to assess data on the prevalence of threshold and subthreshold psychiatric syndromes in the general population (Preisig et al., 2009). In 2003, the participants of CoLaus ( $n=6$ '736) aged between 35 and 75 years were randomly recruited from the population registry in the city of Lausanne (Switzerland) (Firmann et al., 2008). Clinical data and blood samples were collected and participants were interviewed with a comprehensive semi-structured questionnaire. Sixty-seven percent of the subjects in the age range between 35 and 66 years participating in CoLaus $\left(n=5^{\prime}, 535\right)$ also took part in PsyCoLaus, resulting in a total of 3'720 individuals. For the current study, subjects with a lifetime diagnosis of MDD were selected, resulting in a sample of $n=1624$. All diagnostic interviews were conducted by psychologists or psychiatrists intensively trained over a two-month period and each interview protocol was reviewed by a senior psychologist (Preisig et al., 2009).

\subsection{Measurements}

\subsubsection{Assessment of sociodemographic and clinical measures}

\subsubsection{Face-to-face interview}


Sociodemographic characteristics were provided through a standardized interview, and socioeconomic status (SES) was assessed using the Hollingshead scale (Hollingshead, 1975). Information on mental disorders and treatment was collected using the semi-structured Diagnostic Interview for Genetic Studies ((DIGS) Nurnberger et al., 1994; Preisig et al., 1999). The DIGS allows for the computation of a broad spectrum of DSM IV (2000) Axis I algorithms, supplemented by sections on anxiety disorders from the Schedule for Affective Disorders and Schizophrenia - Lifetime Version (Endicott and Spitzer, 1978). The depression section of the DIGS provides comprehensive information about the depressive phenomenology during the current/recent/last/ and the most severe depressive episodes. Furthermore, the DIGS records precise information on the course and chronology of comorbid conditions (Preisig et al., 2009). The age of onset of the mental diagnoses was assessed by asking the following DIGS question: "When did it begin?", based on a metric scale. Abuse of and dependence on alcohol, marijuana, hallucinogens, stimulants, cocaine, sedatives, solvents, and narcotics was grouped in the category substance use as soon as a subject fulfilled the abuse/dependence criteria of one of the corresponding substances. Due to their wide differences in ages of onset, anxiety disorders were grouped into two categories of disorders with comparable ages of onset: early anxiety disorders beginning during childhood or adolescence (< age 16) comprising simple phobia, social phobia, separation anxiety disorder, and overanxious disorder versus late anxiety disorders beginning in adulthood comprising panic disorder, generalized anxiety disorder, and agoraphobia. Subjective judgment of general childhood was rated on a four-point Likert scale ranging from $1=$ "happy" to $4=$ "very unhappy" in a DIGS section focusing on childhood.

The French translation of the DIGS (Leboyer et al., 1995) showed excellent inter-rater reliability (kappa and Yule's Y coefficients) for major mood and psychotic disorders (Preisig et al., 1999), substance use disorders and antisocial personality disorders (Berney et al., 2002), and satisfactory inter-rater and test-retest reliability for the anxiety chapters (Leboyer et al., 1991; RougemontBuecking et al., 2008). One of several revisions in the French version was the addition of specific criteria to distinguish the MDD specifier atypical depression (including leaden paralysis, longstanding patterns of interpersonal rejection sensitivity, mood reactivity) (Preisig et al., 2009). 
For the current study, the criteria of the specifiers according to the DSM-IV (APA, 2000) were used to diagnose atypical and melancholic depressive episodes. The DSM-IV specifier for atypical depression requires mood reactivity (the capacity to be cheered up when confronted with positive events) and at least two of the following four symptoms: i) increased appetite or significant weight gain, ii) hypersomnia, iii) leaden paralysis (i.e., heavy, leaden feelings in arms or legs), and iv) a long-standing pattern of interpersonal rejection sensitivity. As suggested by Angst and colleagues (2006), atypical depression was diagnosed in a non-hierarchical way meeting at least three out of the five DSM-IV atypical specifier criteria. Only the appetite part of the DSM-IV criterion of increased appetite or weight gain was applied to prevent redundancy due to the fact that BMI (including information about weight gain) was used as a potential mediator/suppressor $(\mathrm{M} / \mathrm{S})$ variable in the current study. The DSM-IV specifier for melancholic depression requires either loss of energy or lack of mood reactivity and three out of the following five symptoms: i) depression regularly worse in the morning, ii) early morning awakening, iii) psychomotor retardation or agitation, iv) decreased appetite (without taking into account weight loss as a criterion and v) excessive guilt. The sixth DSM-IV criterion 'distinct quality of depressed mood' was not considered because it was not assessed in the DIGS. Four MDD subtypes were derived on the basis of the history of atypical and melancholic episodes in subjects fulfilling the criteria for a lifetime diagnosis of MDD: 1) MDD with atypical features only (at least one episode met criteria for atypical features, but no episode met criteria for melancholic features), 2) MDD with melancholic features only (at least one episode met criteria for melancholic features, but no episode met criteria for atypical features), 3) MDD with combined melancholic and atypical features (at least one episode met criteria for atypical features and one episode met criteria for melancholic features), and 4) unspecified MDD (no episode met criteria for atypical or melancholic features).

\subsubsection{Self-rating questionnaires}

The French translation of the EURONET: Problem Resolution Strategy was used to assess subjective coping strategies (Bodmer and Grob, 1996; Grob et al., 1993). This self-rating questionnaire consists of 17 items on possible reactions to problematic situations rated on a four-level Likert scale, ranging 
from "very usual for me" to "very unusual for me". According to our own validation study (Perrin et al., 2014), the items of the EURONET can be divided into the three broad domains of emotional problem resolution strategy (9 items), active problem resolution strategy (4 items), and help seeking behaviors (4 items). The standardized Cronbach's alpha coefficients were 0.65 (emotion-focused coping), 0.69 (Help-seeking), and 0.44 (problem-focused coping), respectively (Perrin et al., 2014).

Information concerning personality traits was taken from the Eysenck Personality Questionnaire (EPQ), conceptualizing personality as the three biologically-based independent temperament dimensions Extraversion-Introversion, Neuroticism-Stability, and Psychoticism-Socialization (Eysenck and Eysenck, 1975). The French version of the EPQ was validated by its originators (Eysenck et al., 1980).

In order to measure parental bonding styles, the French version (Mohr et al., 1999) of the Parental Bonding Instrument (PBI) (Mohr et al., 1999; Parker et al., 1979) was applied. The PBI is a self-report instrument with 25 items, assessing the relationship between the subjects up to the age of 16 years and their parents. Similar to other studies, the French version of the PBI showed a three-factor rather than the original two-factor structure to be satisfactory (Mohr et al., 1999). The standardized Cronbach's alpha coefficients for the facets of the three factors were 0.86 (care), 0.84 (denial of autonomy), and 0.72 (encouragement of freedom), which are assessed in both maternal and paternal forms.

\subsubsection{Assessments of physical features}

The body mass index (BMI) providing information on adiposity was calculated as weight in kilograms divided by height in meters squared. Subjects were standing and dressed in light indoor clothes but not wearing shoes while measured and weighted. These physical measures were taken after an 8-hour fast and after refraining from exhausting physical activity for the previous 12 hours. For more details with regard to the physical assessment, see Lasserre et al. (2014). 
The study was approved by the Institutional Ethics Committee of the University of Lausanne. Based on the declaration of Helsinki, all subjects signed written informed consent after being informed about the goal and funding of the study (Preisig et al., 2009).

\subsection{Statistical analysis}

Descriptive statistics were provided by absolute and relative frequencies for categorical variables and medians for metrically and ordinally scaled variables, respectively. Chi-square tests were applied to the categorical variables to test for significant frequency differences. Due to the non-normally distributed metric data, nonparametric Kruskal-Wallis rank-sum tests were used. Bivariate associations between depressive subtypes, sex, and potential M/S variables were computed, using logistic and multinomial logistic regressions (MLR; odds ratios (ORs) with 95\% confidence intervals (CIs)).

Path models were specified treating the variable sex as the independent variable (IV) and the depressive subtypes (four categories: atypical MDD, melancholic MDD, combined atypicalmelancholic MDD, and unspecified MDD acting as reference group) as dependent variable (DV). In the context of the mediation analysis, the relationship between an IV and a DV is decomposed into two causal paths, whereby one of these paths links the IV directly to the DV (direct effect) and the other links the IV to the DV through an M/S (indirect effect). The indirect effect implies that an IV causes an M/S and the M/S causes the DV (Holland, 1988; MacKinnon et al., 2000; Sobel, 1990). According to the four criteria of Baron and Kenny (1986) (significant three simple regressions: 1) IV on DV; 2) IV on M/S; 3) M/S on DV; and 4) a multiple regression of IV and M/S on DV, in which $\mathrm{M} / \mathrm{S}$ remains significant and IV is either no longer significant (full mediation), or still significant but reduced in its strength (partial mediation)) and the definition of MacKinnon, Krull and Lockwood (2000), all variables were examined in terms of potential M or S. Statistical significance of indirect effects were based on Sobel's method (1982) and CI (effect considered significant if the 95\% CI did not contain the value 1.0; Mackinnon et al., 2004) in the current analysis. Stone and Sobel (1990) have 
shown that the standard error is accurate for samples including a minimum of 100-200 subjects in models with more than one mediator. Similar findings were also found elsewhere (MacKinnon et al., 2007; MacKinnon et al., 2002; Mackinnon et al., 2004). In the case of continuous mediating variables with missing data, Monte Carlo integration with 500 integration points generated randomly was applied (Muthén and Muthén, 1998-2012). As recommended by Preacher and Hayes (2008), unstandardized regression coefficients (B) were computed. Separate saturated and unsaturated (regression coefficient corresponding to the direct association fixed to zero to examine whether the association between sex and the depressive subtypes was entirely mediated over the indirect variables) path models were computed. The models were compared using the Akaike information criterion (AIC; Akaike, 1987). All path analyses were adjusted for the influence of the socio-demographic covariates age and SES, age due to its known influence based on previous studies and SES based on its trend significance level in Table 1.

Path models were performed using Mplus version 7 for Macintosh (Muthén and Muthén, 1998-2012). Model coefficients for indirect effects were calculated by multiplying the unstandardized effects from $\mathrm{M} / \mathrm{S}$ on DV with the unstandardized effects from IV on M/S using the MODEL CONSTRAINT command in Mplus. The resulting unstandardized coefficients are equivalent to those from the INDIRECT procedure. The unstandardized direct and indirect associations were exponentiated leading to the calculation of ORs and CI. All other analyses were computed by SPSS statistics version 20 for Macintosh (SPSS Inc., USA). The level of statistical significance for all tests was set at $\mathrm{p}<0.05$.

\section{Results}


The sociodemographic characteristics of the 1624 depressive subjects with a lifetime diagnosis of MDD aged from 35 to 66 years are presented below (Table 1). The frequencies of the MDD subtypes by sex were as follows: males: atypical: $n=76(13.5 \%)$, melancholic: $n=141(25.0 \%)$, combined: $n=53$ (9.4\%), unspecified: $n=293$ (52.0\%); females: atypical: $n=180$ (17.0\%), melancholic: $n=281,(26.5 \%)$, combined: $n=145$ (13.7\%), unspecified: $n=455$ (42.9\%). The four MDD subgroups significantly differed with regard to their frequencies/distributions of sex, age of onset of MDD, current and remitted MDD, lifetime treatment, early and late anxiety disorders, BMI, subjective judgment of general childhood, emotion-orientated coping, paternal encouragement of freedom, and Neuroticism. Trend-level associations $(p \leq 0.10)$ were observed for SES, paternal denial of autonomy, and maternal encouragement of freedom. BMI was significantly higher for men (median $=25.06)$ than for women $($ median $=23.18)($ Mann-Whitney U-test; $\mathrm{Z}=-8.74, p=<0.001$, two-sided $)$.

From these 1624 depressive subjects, $18 \%$ exhibited a current MDD while $82 \%$ had a remitted MDD. In addition, $58.3 \%$ received some form of psychopharmacological during lifetime. The detailed pharmacological substances were as follows: antidepressant drugs $n=620$ (38.2\%), anxiolytics/sedative drugs $n=694(42.7 \%)$, antimanic drugs $n=14(0.9 \%)$, antipsychotic drugs $n=43$ (2.6\%), stimulant drugs $\mathrm{n}=4(0.2 \%)$, antiparkinson drugs $\mathrm{n}=2(0.1 \%)$. Of all 1624 depressive subjects, $69.4 \%$ had consulted a healthcare professional for depression during their life.

\section{--Insert Table 1 about here--}

In Table 2 the selection of variables fulfilling the criteria of the Baron and Kenny (1986) procedure for mediation are reported by bivariate associations. Female sex was associated with a higher risk of early and late anxiety disorders, higher emotion-orientated coping, and a lower BMI and age of MDD onset. The model regressing the depressive subtypes on the M/S revealed that early anxiety disorders and high scores on emotion-orientated coping were associated to all three depressive subtypes: atypical, melancholic, and combined atypical-melancholic, compared to unspecified MDD. Late anxiety 
disorders and a low age of MDD onset were associated with the melancholic depression and combined subtypes only. In contrast, high BMI was specific for the atypical and combined atypical-melancholic depression subtypes. The bivariate direct associations between sex and depression subtypes yielded a significant, 1.50-fold higher risk for women belonging to the atypical depression subtype and a 1.72fold higher risk for women manifesting combined atypical-melancholic depressive features compared to men.

\section{--Insert Table 2 about here--}

The ORs with 95\% CIs of the direct and indirect associations of the final path model are depicted in Table 3. The significant direct associations between sex and both the atypical and combined atypicalmelancholic depression subtypes remained significant in the multivariate path model, indicating a partial mediation. The assumption of full mediation was further rejected by the improved model fit indices in the saturated model $(\mathrm{AIC}=35589.664)$ versus the unsaturated model $(\mathrm{AIC}=35594.098)$. The detailed analyses of the specific direction of influence of the M/S variables based on the criteria of Baron and Kenny (1986) revealed that BMI acted as a suppression variable in both the atypical and combined depressive subtypes. Mediation effects were found with regard to early anxiety disorders (atypical and combined subtypes), late anxiety disorders (melancholic and combined subtypes), age of onset MDD (combined subtype), and emotion-orientated coping (atypical subtype) (four criteria of Baron and Kenny not shown). Figure 1 illustrates the unstandardized regression coefficients and standard errors of the final path model. The IV sex is displayed on the left side and the depression subtypes with the categories atypical, melancholic, and combined atypical-melancholic depression are shown on the right side (reference: unspecified MDD). The direct associations between sex and the three depression subtypes are displayed by the large, overarching arrows $(\mathrm{B}=0.444 ; \mathrm{B}=0.124 ; \mathrm{B}=$ 0.437 for the three subtypes). The five $\mathrm{M} / \mathrm{S}$ are embedded in the middle, with short bent arrows denoting indirect associations from IV to DV over $\mathrm{M} / \mathrm{S}$ and straight arrows illustrating direct associations between IV and $\mathrm{M} / \mathrm{S}$ and $\mathrm{M} / \mathrm{S}$ and $\mathrm{DV}$, respectively. Equivalent signs of direct and indirect associations refer to $\mathrm{M}$ variables (early anxiety disorders, emotion-orientated coping, age of 
onset MDD). In contrast to the $\mathrm{OR}$ and $\mathrm{CI}$, the unstandardized regression coefficients relating to late anxiety disorders only reached trend levels of significance. Opposite signs allow for conclusions about S variables, and confirm the above-mentioned findings about the S BMI.

\author{
--Insert Figure 1 about here- \\ --Insert Table 3 about here--
}

Additional exploratory analyses restricted to males revealed remarkable results (data not shown). Males with atypical depression showed a female-associated profile with high emotion-orientated coping and early anxiety disorders in comparison with males who revealed unspecified depression. Furthermore, males belonging to the atypical subtype exhibited lower substance use than those who suffered from unspecified depression. 


\section{Discussion}

The present study is novel in contributing to the issue of the preponderance of women in atypical and combined atypical-melancholic MDD in that it identified several variables associated with both female sex and these two subtypes of depression, which could be mediators between these strong associations. Indeed, using a community-based sample of 1624 adults with MDD, path models revealed that early and late anxiety disorders, high emotion-orientated coping, and low age of MDD act as mediator variables, whereas high BMI suppressed the direct associations between sex and the atypical and combined depression subtypes. Our analyses differentiated that the previously found general mechanism explaining sex differences of overall MDD (such as early anxiety disorders, age of MDD onset, and emotion orientated coping) are also interrelated variables between sex and the atypical/combined atypical-melancholic depression subtypes and have the potential to distinguish these subtypes from the unspecified depressive subgroup. Furthermore, we demonstrated that the omission of BMI as an atypical/ combined atypical-melancholic subtype-specific variable leads to an underestimation of the true women to men ratio within the context of research using depression subtypes.

Pure forms of depressive subtypes are distinguishable by their comorbidity profile, which becomes apparent considering the mediating effect between early anxiety disorders and the atypical depression subtype versus late anxiety disorders and the melancholic depression subtype. Consequently we can conclude that the association of early anxiety disorders with the combined atypical-melancholic subtype mainly results from the atypical phenomenology, whereas the association between late anxiety disorders and the combined subtype rather results from melancholic features. Hence, the findings of Breslau $(1998 ; 1995)$ partially attributing the overall MDD sex differences to prior anxiety disorders might apply more to the pure atypical/combined atypical-melancholic subtypes than to the pure melancholic depression subtype. The closer temporal co-occurrence of anxiety and melancholia/combined atypical-melancholic states could support previous studies showing that the female-associated anxious subtype (Clayton et al., 1991; Halbreich and Kahn, 2007) overlaps more strongly with melancholic features than with atypical symptoms (Rush, 2007). 
In a previous study, the subgroup of subjects fluctuating between atypical and melancholic symptom profiles generally showed high rates of comorbidity, such as mania, panic disorder, simple phobia, bulimia, antisocial personality disorder, and substance use (Levitan et al., 1997). Comorbidity between mood and anxiety disorders indicates higher severity (Kaufman and Charney, 2000). In line with Levitan et al.'s (1997) findings, the subgroup with combined atypical-melancholic features yielded the highest relative frequencies of both early and late anxiety disorders and slightly higher substance use. This study is the first to demonstrate that early and late anxiety disorders (however, only around the borderline significance level) mediate the path between sex and this female-related severe depression subtype. Beyond its comorbidity profile, also the pronounced early age of onset of the combined atypical-melancholic depression subtype underlines its higher severity. Early age of onset has been shown to indicate severity in outpatients (Zisook et al., 2007), community samples (Kessler et al., 2001), and, with a focus on depression subtype-specific risk factors, in atypical depression (Angst et al., 2002). Angst et al. (2002) discovered that the association of early age of onset on atypical depression disappeared when the analysis was controlled for sex, suggesting that these variables share common variance. Schuch et al. (2014) demonstrated that a younger age of MDD onset and a higher risk of atypical depression were more frequent among women compared to men. The current data further differentiate these findings by specifying the mediating effect of early age of onset in the association between sex and the severe, combined atypical-melancholic subtype, which is only detectable by a carefully assessed history of atypical and melancholic features. Moreover, comparing the depression subtypes with the undifferentiated subtype, as done in the current study, allows for a more detailed differentiation between the symptom-based depression subtypes. The present study additionally included information concerning coping and BMI compared to Schuch et al. (2014).

The association between emotion-orientated coping and the female-preponderant atypical depression (and, with a tendency for the combined atypical-melancholic depression subtype) corroborates findings of studies showing that emotion-orientated coping is more likely in women (Hildebrandt et al., 2003; Tamres et al., 2002). To the best of our knowledge, only one study to date examined 
whether symptom-based depressive subtypes differ as regards coping styles (Ravindran et al., 2002). The authors found no differences between the atypical and typical (melancholic) depressive subgroups in depressed outpatients, contrary to their prediction. Possible explanations for the discrepant results to our study are the means of comparison (atypical versus typical (Ravindran et al., 2002)); comparison with unspecified depressives in the current study) and the different subtype classification based on the HAMD-D scale (Ravindran et al., 2002) versus DSM-based in the current paper. The question remains how the associations between sex, emotion-orientated coping and atypical depression can be explained. Emotion-orientated coping might rather be a severity/distress marker than a specific feature of the atypical depression subtype: both emotion-orientated coping (Ravindran et al., 2002; Roy-Byrne et al., 1992) and atypical depression (Angst et al., 2006; Angst et al., 2002) were associated with depression severity/distress, which in turn is more pronounced in women (Hildebrandt et al., 2003). Furthermore, high neuroticism scores, a personality trait which is more prevalent in women (Lynn and Martin, 1997), could partly explain the mediating influence of emotion-orientated coping. The overlap between sex and neuroticism was shown to account for some of the sex difference in coping in a metaanalysis (Tamres et al., 2002). Actually, the atypical and combined atypical-melancholic depressives exhibited the highest neuroticism scores in the current study, but an earlier study based on the same data also showed a significant, strong positive correlation between neuroticism and emotion-orientated coping (Perrin et al., 2014), which precluded the use of both variables in the current analyses. Because coping styles are learned behavioral patterns, the present finding provides a potential target for depression subtype-specific treatment, as claimed by Baumeister and Parker (2012). Once again, the usefulness of the differentiation of MDD into symptom-based depression subtypes becomes apparent.

The strong association between high BMI and atypical depression found in the present study is in agreement with previous empirical findings (Hasler et al., 2004; Kendler et al., 1996; Lamers et al., 2013; Levitan et al., 2012). In the available literature focusing on overall MDD, the correlation between depression and obesity was sometimes unequal between the sexes, e.g., inversely correlated in men, but not in women (Palinkas et al., 1996) or linked to obesity in women only (Andreyeva et al., 2007). We expanded this knowledge by specifying that BMI enhanced the predictive validity of 
female sex on the atypical and combined atypical-melancholic depression subtypes by suppressing irrelevant variance. Some authors hypothesized that the high overlap of atypical depression and BMI might reflect operational artefacts, because the diagnostic criteria of both disorders comprise increased food intake (Angst et al., 2002; Hasler et al., 2004). We handled this artefact by excluding the redundant criterion in the definition of atypical depression. However, it cannot be excluded that the associations found between atypical depression and BMI merely represent epiphenomena, although this possibility was judged to be fairly unlikely (Lamers, 2013). Another study even demonstrated shared familial/genetic factors of these two disorders (Kendler et al., 1996). In any case, being overweight and exhibiting atypical depression have turned out to be stable characteristics (Hasler et al., 2004; Kendler et al., 1996; Lamers et al., 2012b; Nierenberg et al., 1996; Rodgers et al., 2014a) and obviously represent highly entwined constructs.

In contrast to some studies based on samples of in-/outpatients (Hildebrandt et al., 2003; Xiang et al., 2012), on prospective community samples (Angst et al., 2007; Rodgers et al., 2014a; Rodgers et al., 2014b), and mixed community-clinical samples (Schuch et al., 2014) showing a preponderance of men with melancholic depression, this sex-difference was not observed in the current study. This discrepancy is not likely explainable by methodological differences. Hence, more research focusing on this topic of interest is needed.

The result pertaining to the atypical depressive subtype in men who actually displayed a femalerelated profile is remarkable. In line with this finding, low serum testosterone levels were detected in atypical depressive men in a recent preliminary study (Rodgers et al., 2015). The evidence that the subgroup of atypical depressed men display a risk profile commonly associated with female sex, which contrasted with the unspecified depressive subtype in men, might be of relevance for mental health care providers and requires further investigation.

\section{Limitations}


Before discussing the final conclusions, some limitations need mentioning. First, although path models imply a causal origin between predictor and dependent variable, our data are cross-sectional. Maxwell et al. (2011) demonstrated that cross-sectional estimates can either underestimate or overestimate longitudinal parameters. Therefore, the present study should be seen as a prelude for longitudinal research investigating this topic. However, derived from previous empirical evidence, depression mostly occurs secondarily to comorbid conditions (Hasegawa et al., 1991; Kessler, 2012; Schuckit et al., 1997; Wittchen et al., 2000), as postulated in the present path model. Nevertheless, we do not have knowledge of the temporal ordering between the variables and there are several possible causal pathways as to how they might interrelate. For example, emotion-oriented coping and elevated BMI could be a consequence of atypical depression. With regard to the latter possibility, causality cannot be definitely disentangled in the literature either, and there is longitudinal evidence for obesity preceding (atypical) MDD (Faith et al., 2011), for the reverse (Lasserre et al., 2014) as well as for a reciprocal link (Luppino et al., 2010). With regard to the combined atypical-melancholic depressive subtype it is also not possible to establish the direction of the association with BMI using our cross-sectional analysis. Similar to the results demonstrated for the atypical depressive subtype (Lasserre et al., 2014), it is also theoretically possible that the combined atypical-melancholic depressive episode precedes high BMI. Second, we cannot rule out a potential bias resulting from the higher percentage of subjects with a lifetime diagnosis of MDD having a remitted MDD at time of assessment compared to those subjects with current MDD. A further bias might have resulted from the high percentage of psychopharmacologically treated subjects potentially confounding the results concerning the BMI. However, with regard to the discrimination of depression subtypes, the BMI increase following the atypical depressive episode was shown to be independent of psychotropic drug treatment in the same data (Lasserre et al., 2014). Moreover, we showed that subjects of the melancholic subtype exhibited an even higher psychotropic drug consumption compared with the atypical depression subtype, despite the latter had the highest BMI. We consequently reasoned that the BMI was not severely biased by psychotropic drug intake in the present study. Third, with regard to sex-specific risk factors, not all previously found factors (Kendler and Gardner, 2014) were available in the current paper, and in view of the large number of studies carried out in the context of sex differences of MDD, the present study 
makes no claim to completeness regarding the explored M/S variables. Fourth, recall of depressive symptoms over lifespan is incomplete and existing literature has shown that depressed mood symptoms are more readily recalled by women compared to men (Thompson et al., 2004). However, although we do not know to which degree specific atypical or melancholic symptoms are affected by incomplete recall, it is unlikely that this recall is linked to associated conditions such as anxiety disorders, coping or BMI, which indeed would induce bias. Fifth, no information related to avoidance strategy was available, despite the fact that this coping dimension was also judged to be relevant (Parker and Endler, 1992).

\section{Conclusions}

Notwithstanding these limitations, our study provides new insight into the complex interrelations between sex, the female-related atypical and combined atypical-melancholic depression subtypes and the associated general and specific risk factors by disentangling these associations into separate direct and indirect effects. Our analyses suggest that particularly in women intervention strategies focusing on changing emotion-orientated coping patterns and treatment of anxiety disorders and early depression might contribute to the prevention of atypical and combined atypical-melancholic episodes. However, prospective data need to confirm the temporal relationship between the occurrence of emotion-orientated coping patterns and anxiety disorders and the incidence of atypical and combined atypical-melancholic episodes. 


\section{Acknowledgements}

The authors would like to express their gratitude to the Lausanne inhabitants who volunteered to participate in the PsyCoLaus study and to the collaborators who contributed to the coordination of the study and the collection of data. We would also like to thank all the investigators of the CoLaus study, who made the psychiatric study possible, as well as many GSK employees who contributed to the execution of this study.

\section{Role of the founding source}

The CoLaus|PsyCoLaus study was and is supported by research grants from GlaxoSmithKline, the Faculty of Biology and Medicine of Lausanne, and the Swiss National Science Foundation (grants 3200B0-105993, 3200B0-118308, 33CSCO-122661, 33CS30-139468 and 33CS30-148401). 


\section{References}

2000. American Psychiatric Association. Diagnostic and Statistical Manual of Mental Disorders. 4th ed, text revision. American Psychiatric Association, Washington, DC.

Akaike, H., 1987. Factor analysis and AIC. Psychometrika 52, 317-332.

Alexandrino-Silva, C., Wang, Y.P., Carmen Viana, M., Bulhoes, R.S., Martins, S.S., Andrade, L.H., 2013. Gender differences in symptomatic profiles of depression: results from the Sao Paulo Megacity Mental Health Survey. Journal of affective disorders 147, 355-364.

Andreasen, N.C., Grove, W.M., 1982. The classification of depression: traditional versus mathematical approaches. The American journal of psychiatry 139, 45-52.

Andreyeva, T., Michaud, P.C., van Soest, A., 2007. Obesity and health in Europeans aged 50 years and older. Public Health 121, 497-509.

Angst, J., Gamma, A., Benazzi, F., Ajdacic, V., Rossler, W., 2007. Melancholia and atypical depression in the Zurich study: epidemiology, clinical characteristics, course, comorbidity and personality. Acta Psychiatr Scand Suppl, 72-84.

Angst, J., Gamma, A., Benazzi, F., Silverstein, B., Ajdacic-Gross, V., Eich, D., Rossler, W., 2006. Atypical depressive syndromes in varying definitions. Eur Arch Psychiatry Clin Neurosci 256, 44-54.

Angst, J., Gamma, A., Sellaro, R., Zhang, H., Merikangas, K., 2002. Toward validation of atypical depression in the community: results of the Zurich cohort study. Journal of affective disorders 72, 125138.

Antonijevic, I.A., 2006. Depressive disorders -- is it time to endorse different pathophysiologies? Psychoneuroendocrinology 31, 1-15.

APA, 2000. Diagnostic and Statistical Manual of Mental Disorders. 4th ed, text revision. American Psychiatric Association, Washington, DC.

APA, 2013. Diagnostic and statistical manual of mental disorders. 5th edn. American Psychiatric Publishing, Arlington.

Baron, R.M., Kenny, D.A., 1986. The moderator-mediator variable distinction in social psychological research: conceptual, strategic, and statistical considerations. J Pers Soc Psychol 51, 1173-1182.

Basoglu, M., 1984. Symptomatology of depressive disorder in Turkey. A factor-analytic study of 100 depressed patients. Journal of affective disorders 6, 317-330.

Baumeister, H., Parker, G., 2012. Meta-review of depressive subtyping models. Jounal of affective disorders 139, 126-140.

Benazzi, F., 1999. Prevalence and clinical features of atypical depression in depressed outpatients: a 467-case study. Psychiatry Res 86, 259-265.

Benazzi, F., 2002. Can only reversed vegetative symptoms define atypical depression? Eur Arch Psychiatry Clin Neurosci 252, 288-293.

Berney, A., Preisig, M., Matthey, M.L., Ferrero, F., Fenton, B.T., 2002. Diagnostic interview for genetic studies (DIGS): inter-rater and test-retest reliability of alcohol and drug diagnoses. Drug Alcohol Depend 65, 149-158.

Blanco, C., Vesga-Lopez, O., Stewart, J.W., Liu, S.M., Grant, B.F., Hasin, D.S., 2012. Epidemiology of major depression with atypical features: results from the National Epidemiologic Survey on Alcohol and Related Conditions (NESARC). The Journal of clinical psychiatry 73, 224-232.

Bodmer, N.M., Grob, A., 1996. Bien-être et contraintes d'adolescents: une comparaison entre adolescents de familles monoparentales et de familles biparentales. International Journal of Psychology 31, 39-48.

Boyce, P., Parker, G., Barnett, B., Cooney, M., Smith, F., 1991. Personality as a vulnerability factor to depression. The British journal of psychiatry : the journal of mental science 159, 106-114.

Breslau, N., Chilcoat, H., Schultz, L.R., 1998. Anxiety disorders and the emergence of sex differences in major depression. J Gend Specif Med 1, 33-39.

Breslau, N., Schultz, L., Peterson, E., 1995. Sex differences in depression: a role for preexisting anxiety. Psychiatry Res 58, 1-12.

Carver, C.S., Scheier, M.F., Weintraub, J.K., 1989. Assessing coping strategies: a theoretically based approach. J Pers Soc Psychol 56, 267-283.

Clayton, P.J., Grove, W.M., Coryell, W., Keller, M., Hirschfeld, R., Fawcett, J., 1991. Follow-up and family study of anxious depression. The American journal of psychiatry 148, 1512-1517. 
Dunn, S.H., Conley, Y.P., 2015. A systematic review of genetic influences on coping. Biol Res Nurs 17, 87-93.

Endicott, J., Spitzer, R.L., 1978. A diagnostic interview: the schedule for affective disorders and schizophrenia. Archives of general psychiatry 35, 837-844.

Endler, N.S., Parker, J.D.A., 1990. State and trait anxiety, depression and coping styles. Australian Journal of Psychology 42, 207-220.

Eysenck, H.J., Eysenck, S.B.G., 1975. Manual of the Eysenck Personality Questionnaire. Hodder and Stoughton, London.

Eysenck, H.J., Eysenck, S.B.G., Gauquelin, M., Gauquelin, F., Pascal, C., Pascal, D., 1980. The structure of the personality among French compared to that of an English: cross-cultural comparison. La Personnalité 1-2, 7-29.

Faith, M.S., Butryn, M., Wadden, T.A., Fabricatore, A., Nguyen, A.M., Heymsfield, S.B., 2011. Evidence for prospective associations among depression and obesity in population-based studies. Obes Rev 12, e438-453.

Firmann, M., Mayor, V., Vidal, P.M., Bochud, M., Pecoud, A., Hayoz, D., Paccaud, F., Preisig, M., Song, K.S., Yuan, X., Danoff, T.M., Stirnadel, H.A., Waterworth, D., Mooser, V., Waeber, G., Vollenweider, P., 2008. The CoLaus study: a population-based study to investigate the epidemiology and genetic determinants of cardiovascular risk factors and metabolic syndrome. BMC Cardiovasc Disord 8, 6 .

Folkman, S., Lazarus, R.S., 1980. An analysis of coping in a middle-aged community sample. J Health Soc Behav 21, 219-239.

Folkman, S., Lazarus, R.S., 1988. The Ways of Coping Questionnaire. Consulting Psychologists' Press, Palo Alto (CA).

Fountoulakis, K.N., Iacovides, A., Nimatoudis, I., Kaprinis, G., Ierodiakonou, C., 1999. Comparison of the diagnosis of melancholic and atypical features according to DSM-IV and somatic syndrome according to ICD-10 in patients suffering from major depression. European psychiatry : the journal of the Association of European Psychiatrists 14, 426-433.

Gold, P.W., Chrousos, G.P., 2002. Organization of the stress system and its dysregulation in melancholic and atypical depression: high vs low CRH/NE states. Molecular Psychiatry 7, 254-275.

Grob, A., Bodmer, N., Flammer, A., 1993. Living Conditions and the Development of Adolescents in Europe: The Case of Switzerland. Research Report (Nr. 5). Institute of Psychology. University of Berne, Switzerland.

Halbreich, U., Kahn, L.S., 2007. Atypical depression, somatic depression and anxious depression in women: are they gender-preferred phenotypes? Journal of affective disorders 102, 245-258.

Hasegawa, K., Mukasa, H., Nakazawa, Y., Kodama, H., Nakamura, K., 1991. Primary and secondary depression in alcoholism--clinical features and family history. Drug Alcohol Depend 27, 275-281.

Haslam, N., Beck, A.T., 1993. Categorization of major depression in an outpatient sample. J Nerv Ment Dis 181, 725-731.

Hasler, G., Pine, D.S., Gamma, A., Milos, G., Ajdacic, V., Eich, D., Rossler, W., Angst, J., 2004. The associations between psychopathology and being overweight: a 20-year prospective study. Psychol Med 34, 1047-1057.

Hildebrandt, M.G., Stage, K.B., Kragh-Soerensen, P., 2003. Gender differences in severity, symptomatology and distribution of melancholia in major depression. Psychopathology 36, 204-212.

Hirschfeld, R.M., Klerman, G.L., Lavori, P., Keller, M.B., Griffith, P., Coryell, W., 1989. Premorbid personality assessments of first onset of major depression. Archives of general psychiatry 46, 345-350. Holland, P.W., 1988. Causal inference, path analysis, and recursive structural equations models. Sociological Methodology 18, 449-484.

Hollingshead, A.B., 1975. Four factor Index of Social Status. Yale University Press, New Haven, CT. Kaufman, J., Charney, D., 2000. Comorbidity of mood and anxiety disorders. Depression and anxiety 12 Suppl 1, 69-76.

Kendler, K.S., Eaves, L.J., Walters, E.E., Neale, M.C., Heath, A.C., Kessler, R.C., 1996. The identification and validation of distinct depressive syndromes in a population-based sample of female twins. Archives of general psychiatry 53, 391-399.

Kendler, K.S., Gardner, C.O., 2014. Sex differences in the pathways to major depression: a study of opposite-sex twin pairs. The American journal of psychiatry 171, 426-435. 
Kendler, K.S., Neale, M.C., Kessler, R.C., Heath, A.C., Eaves, L.J., 1993. A longitudinal twin study of personality and major depression in women. Archives of general psychiatry 50, 853-862.

Kessler, R.C., 2012. The costs of depression. Psychiatr Clin North Am 35, 1-14.

Kessler, R.C., Avenevoli, S., Ries Merikangas, K., 2001. Mood disorders in children and adolescents: an epidemiologic perspective. Biol Psychiatry 49, 1002-1014.

Kornstein, S.G., Schatzberg, A.F., Thase, M.E., Yonkers, K.A., McCullough, J.P., Keitner, G.I., Gelenberg, A.J., Ryan, C.E., Hess, A.L., Harrison, W., Davis, S.M., Keller, M.B., 2000. Gender differences in chronic major and double depression. Journal of affective disorders 60, 1-11.

Kuehner, C., 2003. Gender differences in unipolar depression: an update of epidemiological findings and possible explanations. Acta psychiatrica Scandinavica 108, 163-174.

Lamers, F., Burstein, M., He, J.P., Avenevoli, S., Angst, J., Merikangas, K.R., 2012a. Structure of major depressive disorder in adolescents and adults in the US general population. The British journal of psychiatry : the journal of mental science 201, 143-150.

Lamers, F., de Jonge, P., Nolen, W.A., Smit, J.H., Zitman, F.G., Beekman, A.T., Penninx, B.W., 2010. Identifying depressive subtypes in a large cohort study: results from the Netherlands Study of Depression and Anxiety (NESDA). The Journal of clinical psychiatry 71, 1582-1589.

Lamers, F., Rhebergen, D., Merikangas, K.R., de Jonge, P., Beekman, A.T., Penninx, B.W., 2012b. Stability and transitions of depressive subtypes over a 2-year follow-up. Psychol Med 42, 2083-2093.

Lamers, F., Vogelzangs, N., Merikangas, K.R., de Jonge, P., Beekman, A.T., Penninx, B.W., 2013. Evidence for a differential role of HPA-axis function, inflammation and metabolic syndrome in melancholic versus atypical depression. Molecular Psychiatry 18, 692-699.

Lasserre, A.M., Glaus, J., Vandeleur, C.L., Marques-Vidal, P., Vaucher, J., Bastardot, F., Waeber, G., Vollenweider, P., Preisig, M., 2014. Depression with atypical features and increase in obesity, body mass index, waist circumference, and fat mass: a prospective, population-based study. JAMA Psychiatry 71, 880-888.

Leboyer, M., Barbe, B., Gorwood, P., Teherani, M., Allilaire, J.F., Preisig, M., Matthey, M.L., Poyetton, V., Ferrero, F., 1995. Interview Diagnostique pour les Etudes Génétiques Paris: INSERM.

Leboyer, M., Maier, W., Teherani, M., Lichtermann, D., D'Amato, T., Franke, P., Lepine, J.P., Minges, J., McGuffin, P., 1991. The reliability of the SADS-LA in a family study setting. Eur Arch Psychiatry Clin Neurosci 241, 165-169.

Levitan, R.D., Davis, C., Kaplan, A.S., Arenovich, T., Phillips, D.I., Ravindran, A.V., 2012. Obesity comorbidity in unipolar major depressive disorder: refining the core phenotype. The Journal of clinical psychiatry $73,1119-1124$.

Levitan, R.D., Lesage, A., Parikh, S.V., Goering, P., Kennedy, S.H., 1997. Reversed neurovegetative symptoms of depression: a community study of Ontario. The American journal of psychiatry 154, 934-940.

Li, Y., Aggen, S., Shi, S., Gao, J., Tao, M., Zhang, K., Wang, X., Gao, C., Yang, L., Liu, Y., Li, K., Shi, J., Wang, G., Liu, L., Zhang, J., Du, B., Jiang, G., Shen, J., Zhang, Z., Liang, W., Sun, J., Hu, J., Liu, T., Miao, G., Meng, H., Hu, C., Huang, G., Li, G., Ha, B., Deng, H., Mei, Q., Zhong, H., Gao, S., Sang, H., Zhang, Y., Fang, X., Yu, F., Yang, D., Chen, Y., Hong, X., Wu, W., Chen, G., Cai, M., Song, Y., Pan, J., Dong, J., Pan, R., Zhang, W., Shen, Z., Liu, Z., Gu, D., Liu, X., Zhang, Q., Flint, J., Kendler, K.S., 2014. The structure of the symptoms of major depression: exploratory and confirmatory factor analysis in depressed Han Chinese women. Psychol Med 44, 1391-1401.

Luppino, F.S., de Wit, L.M., Bouvy, P.F., Stijnen, T., Cuijpers, P., Penninx, B.W., Zitman, F.G., 2010. Overweight, obesity, and depression: a systematic review and meta-analysis of longitudinal studies. Archives of general psychiatry 67, 220-229.

Lynn, R., Martin, T., 1997. Gender Differences in Extraversion, Neuroticism, and Psychoticism in 37 Nations. The Journal of Social Psychology 137, 369-373.

MacKinnon, D.P., Fairchild, A.J., Fritz, M.S., 2007. Mediation analysis. Annu Rev Psychol 58, $593-$ 614.

MacKinnon, D.P., Krull, J.L., Lockwood, C.M., 2000. Equivalence of the mediation, confounding and suppression effect. Prev Sci 1, 173-181.

MacKinnon, D.P., Lockwood, C.M., Hoffman, J.M., West, S.G., Sheets, V., 2002. A comparison of methods to test mediation and other intervening variable effects. Psychol Methods 7, 83-104.

Mackinnon, D.P., Lockwood, C.M., Williams, J., 2004. Confidence Limits for the Indirect Effect: Distribution of the Product and Resampling Methods. Multivariate Behav Res 39, 99. 
Maes, M., Cosyns, P., Maes, L., D'Hondt, P., Schotte, C., 1990. Clinical subtypes of unipolar depression: Part I. A validation of the vital and nonvital clusters. Psychiatry Res 34, 29-41.

Marcus, S.M., Young, E.A., Kerber, K.B., Kornstein, S., Farabaugh, A.H., Mitchell, J., Wisniewski, S.R., Balasubramani, G.K., Trivedi, M.H., Rush, A.J., 2005. Gender differences in depression: findings from the STAR*D study. Journal of affective disorders 87, 141-150.

Maxwell, S.E., Cole, D.A., Mitchell, M.A., 2011. Bias in Cross-Sectional Analyses of Longitudinal Mediation: Partial and Complete Mediation Under an Autoregressive Model. Multivariate Behav Res 46, 816-841.

Mohr, S., Preisig, M., Fenton, B.T., Ferrero, F., 1999. Validation of the French version of the parental bonding instrument in adults. Personality and Individual Differences 26, 1065-1074.

Moskvina, V., Farmer, A., Jones, I.R., Brewster, S., Ferrero, F., Gill, M., Jones, L.A., Maier, W., Mors, O., Owen, M.J., Perry, J., Preisig, M., Rietschel, M., McGuffin, P., Craddock, N., Korszun, A., 2008. Sex differences in symptom patterns of recurrent major depression in siblings. Depression and anxiety $25,527-534$.

Muthén, L.K., Muthén, B.O., 1998-2012. Mplus User's Guide. Seventh Edition. Muthén\&Muthén, Los Angeles, CA.

Nierenberg, A.A., Pava, J.A., Clancy, K., Rosenbaum, J.F., Fava, M., 1996. Are neurovegetative symptoms stable in relapsing or recurrent atypical depressive episodes? Biol Psychiatry 40, 691-696.

Nolen-Hoeksema, S., 2012. Emotion regulation and psychopathology: the role of gender. Annu Rev Clin Psychol 8, 161-187.

Nurnberger, J.I., Jr., Blehar, M.C., Kaufmann, C.A., York-Cooler, C., Simpson, S.G., HarkavyFriedman, J., Severe, J.B., Malaspina, D., Reich, T., 1994. Diagnostic interview for genetic studies. Rationale, unique features, and training. NIMH Genetics Initiative. Archives of general psychiatry 51, 849-859; discussion 863-844.

O'Keane, V., Frodl, T., Dinan, T.G., 2012. A review of Atypical depression in relation to the course of depression and changes in HPA axis organization. Psychoneuroendocrinology 37, 1589-1599.

Palinkas, L.A., Wingard, D.L., Barrett-Connor, E., 1996. Depressive symptoms in overweight and obese older adults: a test of the "jolly fat" hypothesis. J Psychosom Res 40, 59-66.

Parker, G., Tupling, H., Brown, L.B., 1979. A Parental Bonding Instrument. British Journal of Medical Psychology 52, 1-10.

Parker, J.D.A., Endler, N.S., 1992. Coping with coping assessment: a critical review. 6, 321-344.

Perrin, M., Vandeleur, C.L., Castelao, E., Rothen, S., Glaus, J., Vollenweider, P., Preisig, M., 2014. Determinants of the development of post-traumatic stress disorder, in the general population. Soc Psychiatry Psychiatr Epidemiol 49, 447-457.

Piccinelli, M., Wilkinson, G., 2000. Gender differences in depression. Critical review. The British journal of psychiatry : the journal of mental science 177, 486-492.

Posternak, M.A., Zimmerman, M., 2001. Symptoms of atypical depression. Psychiatry Res 104, 175181.

Preacher, K.J., Hayes, A.F., 2008. Asymptotic and resampling strategies for assessing and comparing indirect effects in multiple mediator models. Behav Res Methods 40, 879-891.

Preisig, M., Fenton, B.T., Matthey, M.L., Berney, A., Ferrero, F., 1999. Diagnostic interview for genetic studies (DIGS): inter-rater and test-retest reliability of the French version. Eur Arch Psychiatry Clin Neurosci 249, 174-179.

Preisig, M., Waeber, G., Vollenweider, P., Bovet, P., Rothen, S., Vandeleur, C., Guex, P., Middleton, L., Waterworth, D., Mooser, V., Tozzi, F., Muglia, P., 2009. The PsyCoLaus study: methodology and characteristics of the sample of a population-based survey on psychiatric disorders and their association with genetic and cardiovascular risk factors. BMC Psychiatry 9, 9.

Ravindran, A.V., Griffiths, J., Waddell, C., Anisman, H., 1995. Stressful life events and coping styles in relation to dysthymia and major depressive disorder: variations associated with alleviation of symptoms following pharmacotherapy. Prog Neuropsychopharmacol Biol Psychiatry 19, 637-653.

Ravindran, A.V., Matheson, K., Griffiths, J., Merali, Z., Anisman, H., 2002. Stress, coping, uplifts, and quality of life in subtypes of depression: a conceptual frame and emerging data. Journal of affective disorders 71, 121-130.

Rodgers, S., Ajdacic-Gross, V., Muller, M., Hengartner, M.P., Grosse Holtforth, M., Angst, J., Rossler, W., 2014a. The role of sex on stability and change of depression symptom subtypes over 20 years: a latent transition analysis. Eur Arch Psychiatry Clin Neurosci 264, 577-588. 
Rodgers, S., grosse Holtforth, M., Hengartner, M.P., Müller, M., Aleksandrowicz, A.A., Rössler, W., Ajdacic-Gross , V., 2015. Serum testosterone levels and symptom-based depression subtypes in men. Front. Psychiatry 6:61.

Rodgers, S., Grosse Holtforth, M., Muller, M., Hengartner, M.P., Rossler, W., Ajdacic-Gross, V., 2014b. Symptom-based subtypes of depression and their psychosocial correlates: a person-centered approach focusing on the influence of sex. Journal of affective disorders 156, 92-103.

Rougemont-Buecking, A., Rothen, S., Jeanpretre, N., Lustenberger, Y., Vandeleur, C.L., Ferrero, F., Preisig, M., 2008. Inter-informant agreement on diagnoses and prevalence estimates of anxiety disorders: direct interview versus family history method. Psychiatry Res 157, 211-223.

Roy-Byrne, P.P., Vitaliano, P.P., Cowley, D.S., Luciano, G., Zheng, Y., Dunner, D.L., 1992. Coping in panic and major depressive disorder. Relative effects of symptom severity and diagnostic comorbidity. J Nerv Ment Dis 180, 179-183.

Rush, A.J., 2007. The varied clinical presentations of major depressive disorder. The Journal of clinical psychiatry 68 Suppl 8, 4-10.

Schotte, C.K., Maes, M., Cluydts, R., Cosyns, P., 1997. Cluster analytic validation of the DSM melancholic depression. The threshold model: integration of quantitative and qualitative distinctions between unipolar depressive subtypes. Psychiatry Res 71, 181-195.

Schuch, J.J., Roest, A.M., Nolen, W.A., Penninx, B.W., de Jonge, P., 2014. Gender differences in major depressive disorder: results from the Netherlands study of depression and anxiety. Journal of affective disorders 156, 156-163.

Schuckit, M.A., Tipp, J.E., Bergman, M., Reich, W., Hesselbrock, V.M., Smith, T.L., 1997. Comparison of induced and independent major depressive disorders in 2,945 alcoholics. The American journal of psychiatry 154, 948-957.

Serretti, A., Lattuada, E., Cusin, C., Macciardi, F., Smeraldi, E., 1998. Analysis of depressive symptomatology in mood disorders. Depression and anxiety 8, 80-85.

Sjoholm, L., Lavebratt, C., Forsell, Y., 2009. A multifactorial developmental model for the etiology of major depression in a population-based sample. Journal of affective disorders 113, 66-76.

Sobel, M.E., 1982. Asymptotic confidence intervals for indirect effects in structural equation models. Sociological Methodology 13, 290-312.

Sobel, M.E., 1990. Effect analysis and causation in linear structural equation models. Psychometrika 55, 495-515.

Stone, C.A., Sobel, M.E., 1990. The robustness of estimates of total indirect effects in covariance structure models estimated by maximum likelihood. Psychometrika 55, 337-352.

Sullivan, P.F., Kessler, R.C., Kendler, K.S., 1998. Latent class analysis of lifetime depressive symptoms in the national comorbidity survey. The American journal of psychiatry 155, 1398-1406.

Sullivan, P.F., Prescott, C.A., Kendler, K.S., 2002. The subtypes of major depression in a twin registry. Journal of affective disorders 68, 273-284.

Tamres, L.K., Janicki, D., Helgeson, V.S., 2002. Sex Differences in Coping Behavior: A MetaAnalytic Review and an Examination of Relative Coping. Personality and Social Psychology Review 6, 2-30.

Thompson, R., Bogner, H.R., Coyne, J.C., Gallo, J.J., Eaton, W.W., 2004. Personal characteristics associated with consistency of recall of depressed or anhedonic mood in the 13-year follow-up of the Baltimore Epidemiologic Catchment Area survey. Acta psychiatrica Scandinavica 109, 345-354.

Wittchen, H.U., Kessler, R.C., Pfister, H., Lieb, M., 2000. Why do people with anxiety disorders become depressed? A prospective-longitudinal community study. Acta Psychiatr Scand Suppl, 14-23.

Xiang, Y.T., Wang, G., Hu, C., Guo, T., Ungvari, G.S., Kilbourne, A.M., Lai, K.Y., Si, T.M., Zheng, Q.W., Chen, D.F., Fang, Y.R., Lu, Z., Yang, H.C., Hu, J., Chen, Z.Y., Huang, Y., Sun, J., Wang, X.P., Li, H.C., Zhang, J.B., Chiu, H.F., 2012. Demographic and clinical features and prescribing patterns of psychotropic medications in patients with the melancholic subtype of major depressive disorder in China. PLoS One 7, e39840.

Zisook, S., Lesser, I., Stewart, J.W., Wisniewski, S.R., Balasubramani, G.K., Fava, M., Gilmer, W.S., Dresselhaus, T.R., Thase, M.E., Nierenberg, A.A., Trivedi, M.H., Rush, A.J., 2007. Effect of age at onset on the course of major depressive disorder. The American journal of psychiatry 164, 1539-1546. 


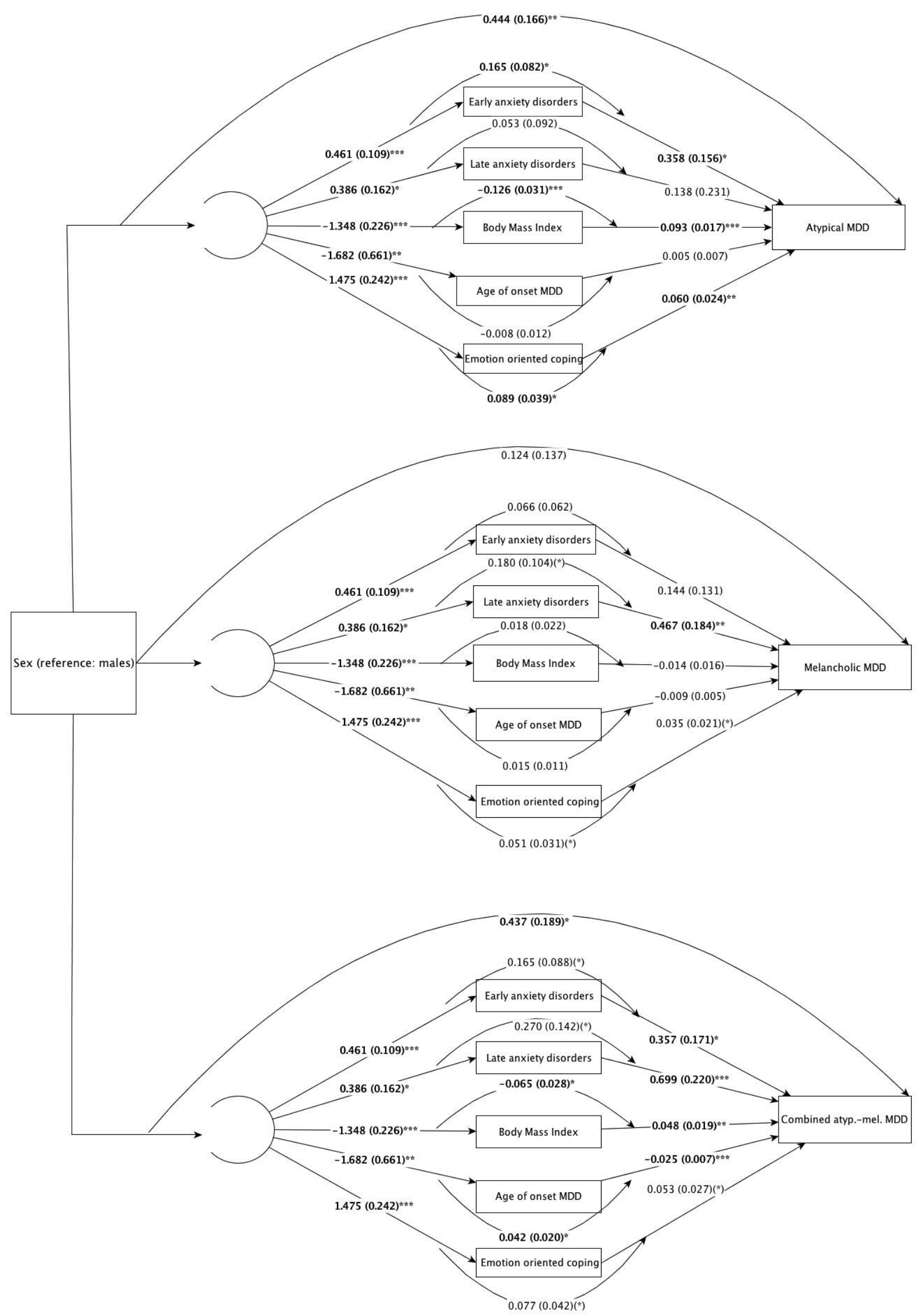

IV, independent variable; DV, dependent variable; MDD, Major Depressive Disorder 
Figure 1. Final path model illustrating the indirect and direct effects of the association between sex (IV) and the MDD subtypes (DV) of the subsample of 1621 subjects with lifetime diagnosis of MDD

Model adjusted for age and socio-economic status

Note:

All parameters depicted in Figure 1 stem from one single path analyis.

DV includes the four categories: atypical MDD, melancholic MDD, combined atypical-melancholic MDD, and unspecified MDD; reference group: unspecified MDD

Rectangles represent the measured variables and single-headed arrows with unstandardized parameter estimates with standard errors denote the direct (straight and large, overarching arrows) and indirect (small bent arrows) regression paths.

Bold indicates significance.

Significance levels:

$* p<0.05$

$* * p \leq 0.01$

$* * * p \leq 0.001$

${ }^{(*)} p \leq 0.10$ (Trend-level) 
Table 1. Socio-demographic and clinical characteristics of subjects with MDD ( $n=1624)$

$$
\text { MDD subtypes }
$$

\begin{tabular}{|c|c|c|c|c|c|c|}
\hline Characteristic & $\begin{array}{l}\text { Atypical } \\
n=256\end{array}$ & $\begin{array}{l}\text { Melancholic } \\
n=422\end{array}$ & $\begin{array}{l}\text { Combined } \\
\text { atypical- } \\
\text { melancholic } \\
n=198\end{array}$ & $\begin{array}{l}\text { Unspecified } \\
n=748\end{array}$ & $\begin{array}{l}p \text {-value } \\
\text { (two-tailed) }\end{array}$ & $n=1624$ \\
\hline $\operatorname{Sex} n(\%)$ & & & & & $<0.01^{\mathrm{a}}$ & \\
\hline Male & $76(29.7)$ & $141(33.4)$ & $53(26.8)$ & $293(39.2)$ & & $563(34.7)$ \\
\hline Female & $180(70.3)$ & $281(66.6)$ & $145(73.2)$ & $455(60.8)$ & & $1061(65.3)$ \\
\hline Age, years, median & 47.5 & 48.3 & 47.7 & 48.3 & $0.320^{\mathrm{b}}$ & 47.9 \\
\hline Civil status $n(\%)$ & & & & & $0.588^{\mathrm{a}}$ & \\
\hline Single & $52(20.3)$ & $61(14.5)$ & $32(16.2)$ & $133(17.8)$ & & $278(17.1)$ \\
\hline Married & $128(50.0)$ & $208(49.3)$ & $104(52.5)$ & $379(50.7)$ & & $819(50.4)$ \\
\hline Separated/divorced & $68(26.6)$ & $137(32.5)$ & $54(27.3)$ & $205(27.4)$ & & $464(28.6)$ \\
\hline Widowed & $8(3.1)$ & $16(3.8)$ & $8(4.0)$ & $31(4.1)$ & & $63(3.9)$ \\
\hline Living status $n(\%)$ & & & & & $0.396^{\mathrm{a}}$ & \\
\hline Alone & $79(30.9)$ & $121(28.7)$ & $61(30.8)$ & $233(31.1)$ & & $494(30.4)$ \\
\hline With family & $163(63.7)$ & $268(63.5)$ & $122(61.6)$ & $443(59.2)$ & & $996(61.3)$ \\
\hline $\begin{array}{l}\text { With friends/apartment- } \\
\text { sharing community }\end{array}$ & $12(4.7)$ & $27(6.4)$ & $14(7.1)$ & $67(9.0)$ & & $120(7.4)$ \\
\hline Other & $2(0.8)$ & $6(1.4)$ & $1(0.5)$ & $5(0.7)$ & & $14(0.9)$ \\
\hline
\end{tabular}


Education ${ }^{1} n(\%)$

$0.275^{\mathrm{a}}$

$n=20$ missing

$$
140 \text { (55.3) }
$$

$219(523)$

106 (54.4)

378 (51.3)

843 (52.6)

Medium

$$
73 \text { (28.9) }
$$

$106(25.3)$

56 (28.7)

195 (26.5)

High

$40(15.8)$

94 (22.4)

Socio-economic status $^{2}, \quad 3.0$

median

$n=3$ missing

Nationality

Swiss

other

$$
189(73.8)
$$

307 (72.7)

140 (70.7)

$531(71.0)$

$0.785^{\mathrm{a}}$

Migration

$n=508$ missing

yes

$35(19.3)$
$146(80.7)$

49 (16.4)

$21(15.8)$

99 (19.7)

$0.081^{\mathrm{b}}$

$331(20.6)$

no

35.0

250 (83.6)

$112(84.2)$

Age of onset MDD,

32.5

29.0

$404(80.3)$

34.0

217 (29.0)

1167 (71.9)

457 (28.1)

years, median

$n=2$ missing

Current MDD

Remitted MDD

$$
69(27.0)
$$

68 (16.1)

$59(29.8)$

$187(73.0)$

354 (83.9)

$139(70.2)$

\section{7 (13.0)}

$651(87.0)$

$<0.001^{\mathrm{a}}$

293 (18.0)

Treatment (lifetime)

Psychotropic drugs ${ }^{3}$

$140(54.7) \quad 289(68.5)$

$150(75.8)$

367 (49.1)

$<0.001^{\mathrm{a}}$

$1331(82.0)$

Consultation healthcare

$175(68.4) \quad 334(79.1)$

$165(83.8)$

$452(60.5)$

$<0.001^{\mathrm{a}}$

$946(58.3)$

$1126(69.4 \%)$ 
professional

$n=2$ missing

Early anxiety disorders ${ }^{4}$

$\begin{array}{lllll}173(41.0) & 98(49.5) & 258(34.5) & <0.001^{\mathrm{a}} & 643(39.6) \\ 68(16.1) & 43(21.7) & 74(9.9) & <0.001^{\mathrm{a}} & 219(13.5) \\ 74(17.5) & 36(18.2) & 126(16.8) & 0.222^{\mathrm{a}} & 267(16.4) \\ 23.4 & 24.1 & 23.7 & <0.001^{\mathrm{b}} & 23.9\end{array}$

Body Mass Index, median 25.2

$34(13.3)$

1.0

2.0

1.0

$<0.01^{\text {b }}$

1.0

median

$n=1$ missing

Coping, median

$n=531$ missing

Emotion-orientated coping 10.0

Problem-orientated coping 8.0

\section{Parental Bonding, median}

Mother: care

$n=518$ missing

Father: care

$n=566$ missing

Mother: denial of

autonomy

$n=518$ missing 
Father: denial of

5.0

autonomy

$n=566$ missing

Mother: encouragement of 10.0

freedom

$n=518$ missing

Father: encouragement of 10.0

freedom

$n=566$ missing

Personality traits, median

$n=496$ missing

Neuroticism

Extraversion

Psychoticism
5.0

9.0

8.0

$0.071^{\mathrm{b}}$

MDD, Major Depressive Disorder

${ }^{\mathrm{a}} \mathrm{Chi}$-Square test/Fisher-test.

${ }^{b}$ Kruskal-Wallis test.

${ }^{1}$ low: compulsory education, apprenticeship/vocational school; medium: preparatory school for general qualification for university entrance, vocational education, vocational secondary school/intermediate diploma school; high: university/university of applied science.

${ }^{2}$ Socio-economic status following Hollingshead's index: A value of 3 represents an SES of III (middle class).

${ }^{3}$ Psychotropic drugs: Antidepressant drugs, tranquilizer (anxiolytics/sedative drugs), antimanic drugs, antipsychotic drugs, stimulant drugs, antiparkison drugs

${ }^{4}$ Simple phobia, social phobia, separation anxiety disorder, overanxious disorder

${ }^{5}$ Panic disorder, generalized anxiety disorder, agoraphobia

${ }^{6} \mathrm{Alcohol} /$ drug abuse/dependence

${ }^{7}$ Rated on a Likert Scale ranging from 1 (happy) to 4 (very unhappy) 
Table 2. Bivariate results (ORs, 95\% CI) of variables meeting the mediator criteria according to Baron and Kenny (1986), adjusted for age and socio-economic status $(n=1621)$

\begin{tabular}{|c|c|c|c|c|c|c|c|c|}
\hline \multirow[t]{2}{*}{ Sex } & \multirow[t]{2}{*}{$\begin{array}{l}\text { Mediator } \\
\text { (M) }\end{array}$} & \multirow[t]{2}{*}{$\begin{array}{l}\text { Associations } \\
\text { between sex } \\
\text { and } M\end{array}$} & \multicolumn{3}{|c|}{$\begin{array}{l}\text { Associations between } \mathbf{M} \text { and depression } \\
\text { subtypes } \\
\text { (reference: unspecified depression) }\end{array}$} & \multicolumn{3}{|c|}{$\begin{array}{l}\text { Direct associations between sex and } \\
\text { depression subtypes } \\
\text { (reference: unspecified depression) }\end{array}$} \\
\hline & & & $\begin{array}{l}\text { Atypical } \\
\text { MDD }\end{array}$ & $\begin{array}{l}\text { Melancholic } \\
\text { MDD }\end{array}$ & $\begin{array}{l}\text { Combined } \\
\text { atypical- } \\
\text { melancholic } \\
\text { MDD }\end{array}$ & $\begin{array}{l}\text { Atypical } \\
\text { MDD }\end{array}$ & $\begin{array}{l}\text { Melancholic } \\
\text { MDD }\end{array}$ & $\begin{array}{l}\text { Combined } \\
\text { atypical- } \\
\text { melancholic } \\
\text { MDD }\end{array}$ \\
\hline \multirow{4}{*}{ Female sex } & $\begin{array}{l}\text { Early anxiety } \\
\text { disorders }{ }^{1}\end{array}$ & $\begin{array}{l}1.86(1.61- \\
2.15)^{* * *}\end{array}$ & $\begin{array}{l}1.48(1.11- \\
1.98)^{* *}\end{array}$ & $\begin{array}{l}1.31(1.03- \\
1.68)^{*}\end{array}$ & $\begin{array}{l}1.84(1.34- \\
2.53)^{* * *}\end{array}$ & \multirow{4}{*}{$\begin{array}{l}1.50(1.10- \\
2.04)^{* *}\end{array}$} & \multirow{4}{*}{$\begin{array}{l}1.27(0.99- \\
1.64)\end{array}$} & \multirow{4}{*}{$\begin{array}{l}1.72(1.21- \\
2.44)^{* * *}\end{array}$} \\
\hline & $\begin{array}{l}\text { Late anxiety } \\
\text { disorders } 2\end{array}$ & $\begin{array}{l}2.19(1.71- \\
2.81)^{* * *}\end{array}$ & $\begin{array}{l}1.32(0.85- \\
2.05)\end{array}$ & $\begin{array}{l}1.73(1.21- \\
2.46)^{* * *}\end{array}$ & $\begin{array}{l}2.46(1.63- \\
3.73) * * *\end{array}$ & & & \\
\hline & $\begin{array}{l}\text { Body Mass } \\
\text { Index }\end{array}$ & $\begin{array}{l}0.89(0.88- \\
0.91)^{* * *}\end{array}$ & $\begin{array}{l}1.09(1.05- \\
1.12)^{* * *}\end{array}$ & $\begin{array}{l}0.98(0.95- \\
1.01)\end{array}$ & $\begin{array}{l}1.04(1.01- \\
1.08)^{*}\end{array}$ & & & \\
\hline & $\begin{array}{l}\text { Age of MDD } \\
\text { onset }\end{array}$ & $\begin{array}{l}0.98(0.97- \\
0.99)^{* * *}\end{array}$ & $\begin{array}{l}1.00(0.99- \\
1.01)\end{array}$ & $\begin{array}{l}0.99(0.98- \\
1.00)^{*}\end{array}$ & $\begin{array}{l}0.97(0.96- \\
0.98)^{* * *}\end{array}$ & & & \\
\hline
\end{tabular}




\begin{tabular}{|l|l|l|l|l|l|l|l|}
\hline & $\begin{array}{l}1.16(1.13- \\
\begin{array}{l}\text { Emotion- } \\
\text { oriented } \\
\text { coping }\end{array}\end{array}$ & $1.19)^{* * *}$ & $\begin{array}{l}1.08(1.03- \\
1.13)^{* * *}\end{array}$ & $\begin{array}{l}1.05(1.00- \\
1.09)^{*}\end{array}$ & $\begin{array}{l}1.08(1.02- \\
1.14)^{* * *}\end{array}$ & & \\
\hline
\end{tabular}

M, Mediator; MDD, Major Depressive Disorder; Odds ratio (OR), Confidence interval (CI)

${ }^{1}$ Early anxiety disorders: simple phobia, social phobia, separation anxiety disorder, overanxious disorder

${ }^{2}$ Late anxiety disorders: panic disorder, generalized anxiety disorder, agoraphobia

Discrepancy to total number of subjects with MDD resulted from $n=3$ missing items.

$$
\begin{aligned}
& * \mathrm{p}<.05 \\
& * * \mathrm{p}<.01 \\
& * * * \mathrm{p}<.001
\end{aligned}
$$

\section{References}

Baron, R.M., Kenny, D.A., 1986. The moderator-mediator variable distinction in social psychological research: conceptual, strategic, and statistical considerations. J Pers Soc Psychol 51, 1173-1182. 
Table 3. Results of the path model examining the direct and indirect effects of sex on the depressive subtypes ( $n=1621)$ via mediation/suppression variables

\begin{tabular}{|c|c|c|c|c|c|c|c|}
\hline \multirow[t]{3}{*}{ Sex } & \multirow[t]{3}{*}{ Mediator (M) } & \multicolumn{3}{|c|}{$\begin{array}{l}\text { Indirect associations of sex and } M \text { and depression } \\
\text { subtypes }\end{array}$} & \multicolumn{3}{|c|}{ Direct association of sex and depression subtypes } \\
\hline & & $\begin{array}{l}\text { Atypical } \\
\text { MDD }\end{array}$ & $\begin{array}{l}\text { Melancholic } \\
\text { MDD }\end{array}$ & $\begin{array}{l}\text { Combined atypical- } \\
\text { melancholic } \\
\text { MDD }\end{array}$ & $\begin{array}{l}\text { Atypical } \\
\text { MDD }\end{array}$ & $\begin{array}{l}\text { Melancholic } \\
\text { MDD }\end{array}$ & $\begin{array}{l}\text { Combined } \\
\text { atypical- } \\
\text { melancholic } \\
\text { MDD }\end{array}$ \\
\hline & & \multicolumn{3}{|c|}{ OR $(95 \% \mathrm{CI})$} & \multicolumn{3}{|c|}{ OR $(95 \% \mathrm{CI})$} \\
\hline \multirow{5}{*}{ Female sex } & $\begin{array}{l}\text { Early anxiety } \\
\text { disorders }{ }^{1}\end{array}$ & $1.43(1.05-1.94)^{*}$ & $1.16(0.89-1.49)$ & $1.43(1.02-2.00)^{*}$ & \multirow{5}{*}{$\begin{array}{c}1.56(1.13- \\
2.16)^{* *}\end{array}$} & \multirow{5}{*}{$1.13(0.87-1.48)$} & \multirow{5}{*}{$\begin{array}{l}1.55(1.07- \\
2.24)^{*}\end{array}$} \\
\hline & $\begin{array}{l}\text { Late anxiety } \\
\text { disorders }\end{array}$ & $1.15(0.73-1.81)$ & $1.60(1.11-2.29)^{*}$ & $2.01(1.31-3.10)^{* *}$ & & & \\
\hline & $\begin{array}{l}\text { Body Mass } \\
\text { Index }\end{array}$ & $1.10(1.06-1.13)^{* *}$ & $0.99(0.96-1.02)$ & $1.05(1.01-1.09)^{*}$ & & & \\
\hline & $\begin{array}{l}\text { Age of MDD } \\
\text { onset }\end{array}$ & $1.01(0.99-1.02)$ & $0.99(0.98-1.00)$ & $0.98(0.96-0.99)^{* *}$ & & & \\
\hline & $\begin{array}{l}\text { Emotion- } \\
\text { orientated } \\
\text { coping }\end{array}$ & $1.06(1.01-1.11)^{*}$ & $1.04(0.99-1.08)$ & $1.05(1.00-1.11)$ & & & \\
\hline
\end{tabular}

M, Mediator; MDD, Major Depressive Disorder; OR, Odds Ratio; CI, 95\% confidence intervals

All model estimates are adjusted for age and socio-economic status

Discrepancy to total number of subjects with MDD resulted from $n=3$ missing items.

*p<.05 
$* * \mathrm{p}<.01$

${ }^{1}$ Early anxiety disorders: simple phobia, social phobia, separation anxiety disorder, overanxious disorder

${ }^{2}$ late anxiety disorders: panic disorder, generalized anxiety disorder, agoraphobia 